\title{
Mesenchymal stromal cells derived from cervical cancer produce high amounts of adenosine to suppress cytotoxic $T$ lymphocyte functions
}

\author{
María de Lourdes Mora-García ${ }^{2}$, Rosario García-Rocha ${ }^{1,2}$, Omar Morales-Ramírez², Juan José Montesinos³, \\ Benny Weiss-Steider ${ }^{1}$, Jorge Hernández-Montes ${ }^{1}$, Luis Roberto Ávila-lbarra 1,2 , Christian Azucena Don-López', \\ Marco Antonio Velasco-Velázquez ${ }^{4}$, Vianey Gutiérrez-Serrano ${ }^{1,2}$ and Alberto Monroy-García 1,2,5*
}

\begin{abstract}
Background: In recent years, immunomodulatory mechanisms of mesenchymal stem/stromal cells (MSCs) from bone marrow and other "classic" sources have been described. However, the phenotypic and functional properties of tumor MSCs are poorly understood. The aim of this study was to analyze the immunosuppressive capacity of cervical cancer-derived MSCs (CeCa-MSCs) on effector T lymphocytes through the purinergic pathway.

Methods: We determined the expression and functional activity of the membrane-associated ectonucleotidases CD39 and CD73 on CeCa-MSCs and normal cervical tissue-derived MSCs (NCX-MSCs). We also analyzed their immunosuppressive capacity to decrease proliferation, activation and effector cytotoxic T (CD8+) lymphocyte function through the generation of adenosine (Ado).
\end{abstract}

Results: We detected that CeCa-MSCs express higher levels of CD39 and CD73 ectonucleotidases in cell membranes compared to NCx-MSCs, and that this feature was associated with the ability to strongly suppress the proliferation, activation and effector functions of cytotoxic T-cells through the generation of large amounts of Ado from the hydrolysis of ATP, ADP and AMP nucleotides.

Conclusions: This study suggests that CeCa-MSCs play an important role in the suppression of the anti-tumor immune response in CeCa through the purinergic pathway.

Keywords: Tumor-mesenchymal stromal cells, T cells, Adenosine, CD39-CD73, Immunosuppression

\section{Background}

Mesenchymal stem/stromal cells (MSCs) are multipotent cells that can be obtained from various mature tissues and are characterized by a wide range of properties, including the ability to adhere to plastic; the simultaneous expression of CD73, CD90, and CD105; and the lack of or reduced expression of specific hematopoietic cell markers such as CD14, CD31, CD34, CD45 and HLA-DR

\footnotetext{
*Correspondence: albertomon@yahoo.com

${ }^{5}$ Oriente 170 No. 160 Colonia Moctezuma 2a Sección Delegación

Venustiano Carranza, 15530 Mexico City, Mexico

Full list of author information is available at the end of the article
}

[1, 2]. They can differentiate into multiple cell types, including osteocytes, chondrocytes, adipocytes, fibroblasts, myoblasts, oocytes, cardiomyocytes, hepatocytes, tenocytes, different epithelial cells (i.e., lung, intestine, kidney, and spleen), and even neurons [3-5].

MSCs may be attracted to damaged tissues by inflammatory cytokines and chemokines and support tissue regeneration and repair [6]. During this process, MSCs contact multiple cell types to carry out therapeutic effects, either by the release of extracellular vesicles (EV) expressing bioactive molecules, such as proteins, lipids, and RNA, which might play anti-inflammatory or antitumoral effects $[7,8]$, or by direct cell-cell interaction 
through integrins and intercellular gap junctions [9]. On the other hand, the invasive growth of tumors also causes inflammation and local tissue damage, attracting MSCs to contribute to repair [6]. Approximately $0.01 \%$ of the cells within solid tumor tissues are thought to be MSCs (T-MSCs) [10]. These T-MSCs stimulate tumor growth by stimulating tumor cell proliferation [11], inducing epithelial-mesenchymal transition of tumor cells [12], prompting the conditions to increase the number of cancer stem cells [13], and promoting tumor angiogenesis and metastasis [6]. T-MSCs have been isolated and characterized from ovarian cancer [14], giant cell tumors of bone [15], neuroblastoma [16], osteosarcoma, lipoma [17], gastric cancer [18] and cervical cancer (CeCa) [19]. In $\mathrm{CeCa}$, our research group was the first to detect the presence of MSCs and suggest their involvement in tumor cell evasion from the immune response of cytotoxic T lymphocytes [19].

In addition, T-MSCs play an important role in the immunosuppression of immune effector cells through the generation of an anti-inflammatory environment by producing Th2-type cytokines (IL-4, IL-5, IL-10) and Th3-type cytokines (TGF- $\beta$ ) $[6,13,20]$, inducing and recruiting regulatory T-cells $[21]$ and producing immunosuppressive factors such as PGE2, IDO and NO [22].

Recently, have been reported that MSCs derived from either bone marrow (BM-MSCs) or umbilical cord blood (UCB-MSCs), may suppress the response of $\mathrm{T}$ lymphocytes through the purinergic pathway [23, 24]. In this pathway, nucleotides (ATP and ADP) released by a variety of cell types in response to stress signals such as injury, hypoxia and inflammation, which commonly occur in the tumor microenvironment, are jointly hydrolyzed by CD39 ectoenzyme (ENTPD1, ectonucleoside triphosphate diphosphohydrolase-1, EC 3.6.1.5) to generate the respective nucleotides. Subsequently, the nucleotides are hydrolyzed by the action of $5^{\prime}$-ectonucleotidase ectoenzyme or CD73 (EC 3.1.3.5), converting AMP to adenosine (Ado) [25]. Most extracellular Ado signaling activities are mediated by G-protein-coupled cell surface adenosine receptors (ARs), which are divided into four subtypes: A1, A2A, A2B and A3 [26]. Ado may exert its immunosuppressive effect on cytotoxic CD8+ $\mathrm{T}$ lymphocytes (CTLs) through the high-affinity Ado receptor A2A $[25,27,28]$. High cAMP production resulting from the signaling of this receptor on T-cells inhibits the proliferation and secretion of anti-tumor cytokines, including TNF- $\alpha$ and IFN- $\gamma[29,30]$, as well as the exocytosis of cytolytic granules containing granzymes and perforin [31].

The expression of CD39 and CD73 in tumors is mainly induced by hypoxia [32] and by the presence of immunosuppressive factors such as TGF- $\beta$ [33]. This expression is generally associated with poor prognosis [32, 34]. Persistent high-risk human papillomavirus (HR-HPV) infection plays an important role in cervical carcinogenesis, which is strongly associated with the production of immunosuppressive cytokines such as IL-10 and TGF- $\beta$. Increased IL-10 and TGF- $\beta$ expression correlates directly with the degree of $\mathrm{CeCa}$ progression and the suppression of the anti-tumor immune response through mechanisms that have not yet been fully elucidated [35-37].

To better understand the role that MSCs play in tumor biology, in this study, we analyzed the immunosuppressive capacity of cervical cancer-derived MSCs (CeCa-MSCs) on effector T lymphocytes through the purinergic pathway. Interestingly, we found that $\mathrm{CeCa}$ MSCs express higher levels of CD39 and CD73 ectonucleotidases in cell membranes compared to MSCs obtained from normal cervical tissues (NCx-MSCs). This feature is associated with the ability to strongly suppress the proliferation, activation and effector functions of cytotoxic T-cells through the generation of large amounts of Ado from the hydrolysis of ATP, ADP and AMP nucleotides. This study suggests for the first time that $\mathrm{CeCa}-\mathrm{MSCs}$ play an important role in the suppression of the anti-tumor immune response in $\mathrm{CeCa}$ through the purinergic pathway.

\section{Methods}

\section{Mesenchymal stromal cells (MSCs)}

The MSCs used in this study were obtained from Normal cervix $(\mathrm{NCx})$ tissues, that were obtained from three subjects who had hysterectomy surgery not related to cancer, and $\mathrm{CeC}$ a samples were obtained from biopsies from three patients in stage IIIB. The local ethics committee approved these procedures. The $\mathrm{CeCa}$ samples intended for tissue culture were collected from biopsies sent to the Pathology Department for routine diagnosis. $\mathrm{NCx}$ - and CeCa-derived mesenchymal stromal cells (MSCs) were obtained by enzymatic digestion as previously described [19], and maintained in low glucose Dulbecco's Modified Eagle Medium (DMEM; Gibco Laboratories, Grand Island, NY, USA) supplemented with $15 \%$ fetal bovine serum (FBS; Gibco), $100 \mathrm{IU} / \mathrm{ml}$ penicillin, $100 \mu \mathrm{g} / \mathrm{ml}$ streptomycin (Gibco) and $5 \mathrm{mM} \mathrm{L}$-glutamine at $37{ }^{\circ} \mathrm{C}$ with $5 \% \mathrm{CO}_{2}$.

MSCs were characterized based on the morphological, phenotypic and differentiation parameters performed according to protocols previously reported by our working group [19]. FITC, PE or APC-conjugated monoclonal antibodies against CD73, CD90 and CD45 (BD Biosciences, San Diego, CA, USA) CD105, CD13, CD14, (Caltag, Buckingham, UK), HLA-ABC, HLA-DR, CD31 and CD34 (Invitrogen, Carlsbad, CA, USA) were used for immunophenotypic characterizations and analyzed on a 
CyAN cytometer (Beckman Coulter, Fullerton CA, USA). Adipogenic and osteogenic differentiation was induced with Stem Cells Kits ${ }^{\text {TM }}$ (STEMCELL Technologies, Inc., Vancouver, BC, Canada). Adipogenic differentiation was determined by visualizing the presence of Oil Red O-stained (Sigma-Aldrich, St. Louis, MO, USA) lipid vacuoles. Osteogenic differentiation was assessed by alkaline phosphatase staining. Chondrogenic differentiation was induced with a commercial induction medium (Cambrex Bio Science, Walkersville, Inc., Maryland, USA) that was supplemented with $10 \mathrm{ng} / \mathrm{ml}$ of TGF- $\beta$ (Cambrex). The resulting micromasses were fixed, embedded and sliced. Cross-sections were stained with Alcian blue dye (Sigma-Aldrich).

\section{Expression of CD39 and CD73 in MSCs}

The expression of the ectonucleotidases CD39 and CD73 in MSC cell membranes was determined by labeling with anti-CD39-FITC (eBioscience, San Diego, CA, USA) and anti-CD73-PE (BD Bioscience) monoclonal antibodies according to the manufacturers' instructions. Cell analysis was performed from the acquisition of 25,000 events in a CyAN cytometer (Beckman Coulter, Fullerton CA, USA). In addition, the expression of the ectonucleotidases CD39 and CD73 in MSCs cell membranes was also determined by immunocytochemical staining by using human anti-CD39 and anti-CD73 mAbs (Novus, Cambridge, UK). Briefly, MSCs grown on glass coverslips to semiconfluence, were fixed in $2 \%$ paraformaldehyde (Sigma, St. Louis, MO) in PBS for 6 min and permeabilized with $0.01 \%$ Triton X-100 in PBS. Following incubation with $2 \%(\mathrm{w} / \mathrm{v})$ bovine serum albumin (Sigma, St. Louis, MO), cells were incubated for $1 \mathrm{~h}$ with the mAbs. Following washing, the coverslips were incubated for $1 \mathrm{~h}$ with a secondary antibody horseradish peroxidase-conjugated goat anti-mouse (DAKO, Carpinteria, USA). The development was performed with substrate-chromogen solution 3,3'-diaminobenzidine dihydrochloride (DAB) for 3-5 min. Secondary antibody alone was included as control for the experiments. The nuclei were stained with Mayer's Hematoxylin. Glass coverslips were scanned to obtain electronic files. The immunocytochemical stains of two stains made independently were digitally analyzed using the Aperio CS (San Diego, CA, USA) digital pathology equipment.

\section{Hydrolytic activity of CD39 and CD73}

Samples containing $10^{5}$ MSCs were cultured in presence of $5 \mathrm{mM}$ ATP, ADP or AMP in $200 \mu \mathrm{l}$ of low glucose DMEM supplemented with $10 \%$ FBS to determine the enzymatic activity of the CD39 and CD73 ectonucleotidases. FBS was previously dialyzed with a membrane (molecular weight cutoff of $12 \mathrm{kDa}$ ). To inhibit the enzymatic activity of CD39 and CD73, MSCs were incubated in the presence of $5 \mathrm{mM}$ specific inhibitors, including sodium polyoxotungstate (POM-1, Sigma-Aldrich, St Louis, MO, USA) and adenosine $5^{\prime}-(\alpha, \beta$-methylene $)$ diphosphate (APCP, Sigma-Aldrich). After $30 \mathrm{~min}$ of incubation with each inhibitor, the adenine nucleotides ATP, ADP and AMP were added to a final concentration of $5 \mathrm{mM}$. The total culture volumes were $200 \mu \mathrm{l}$. Supernatant samples were collected every $60 \mathrm{~min}$, and the presence of Ado was analyzed by thin layer chromatography (TLC) and ultra-performance liquid chromatography (UPLC) (UPLC aquity, Waters, Milford MA, USA). To analyze the samples by TLC, $1 \mu$ of each supernatant was loaded on fluorescent plates precoated with gel (Whatman, GE Healthcare, Freiburg, Germany). Samples were eluted for $1 \mathrm{~h}$ using a mobile phase a mixture composed of isobutanol:isoamyl alcohol:ethoxyethanol:ammonia :water in the ratio 9:6:18:9:15 [38, 39]. ATP, ADP, AMP, Ado and inosine (Sigma-Aldrich) at $5 \mathrm{mg} / \mathrm{ml}$ were used as standards. Finally, the compounds were visualized and photographed under an UV transilluminator (UVP Biodo-H System, Upland, CA, USA).

\section{Ultra-performance liquid chromatography (UPLC)}

An UPLC system (UPLC acquity, Waters) was used to quantify the amount of Ado generated in MSCs cultures in the presence of each nucleotide. Quantitative analysis of samples using standard quantities of synthetic Ado was carried out with Empower 3 software (Waters, USA). The mobile phase consisted of $0.5 \%$ acetonitrile, $5 \%$ methanol, and $94.5 \%$ sodium acetate buffer $0.25 \mathrm{M}$, pH 6.3. Supernatant samples were centrifuged at $13,000 \mathrm{rpm}$ and filtered on Amicon membranes with a cutoff of $3000 \mathrm{Da}$ and subsequently diluted 1:200 with the mobile phase mixture. Run conditions were as follows: flow rate of $1.0 \mathrm{ml} / \mathrm{min}$, UV detection at $254-260 \mathrm{~nm}, 2.0 \mathrm{~min}$ of retention time, room temperature, and a LiChrosfer $5 \mu \mathrm{m}$ RP-18e 100 A (size $125 \mathrm{~mm} \times 4 \mathrm{~mm}, 5 \mu \mathrm{m}$ particle size) reverse phase column. Ado was quantified by comparing the retention time of the sample with that of the synthetic Ado used as standard.

\section{In vitro suppression assay for testing $\mathrm{T}$ cell proliferation}

To determine the suppressive activity of Ado on T-cell proliferation, $1 \times 10^{5} \mathrm{CD} 8+\mathrm{T}$-cells isolated from peripheral blood mononuclear cells (PBMC) from normal donors by negative selection (EasySep Enrichment Cocktail, Stem Cell Technologies, Vancouver, BC, Canada) were cultured in triplicate in 96-well flat bottom plates (Corning, NY, USA) in $100 \mu$ Iscove's Modified Dulbecco's Medium (IMDM) (Gibco) without phenol red, supplemented with $10 \%$ dialyzed FBS. Beads coated with anti-CD2/CD3/CD28 antibodies (Miltenyi Biotec 
GmbH, Bergisch Gladbach, Germany) were added to $\mathrm{T}$-cell cultures in a 2:1 ratio of T-cells:beads. To determine the suppressive capacity of Ado contained in the supernatants from MSCs cultured in the presence of nucleotides, $20 \mu \mathrm{l}$ of each supernatant was added to the T-cell cultures (total volume of $200 \mu \mathrm{l}$ ) and then incubated at $37{ }^{\circ} \mathrm{C}$ and $5 \% \mathrm{CO}_{2}$ for $72 \mathrm{~h}$. Caffeine, a nonselective antagonist of the Ado receptor, was added to some culture plates at a concentration of $300 \mu \mathrm{M}$ (J.T. Baker, Center Valley, PA, USA). In other cases, $1 \mu \mathrm{M}$ ZM241385, a selective antagonist of A2A receptor, or ZM241385 $(1 \mu \mathrm{M})$ plus caffeine $(300 \mu \mathrm{M})$ were added. Lymphocytes stimulated with beads coated with antiCD2/CD3/CD28 antibodies alone or in the presence of synthetic Ado $(500 \mu \mathrm{M})$, caffeine $(300 \mu \mathrm{M})$, Ado:caffeine (500 $\mu \mathrm{M}: 300 \mu \mathrm{M})$, Ado:ZM241385 (500 $\mu \mathrm{M}: 1 \mu \mathrm{M})$, Ado: ZM241385:caffeine (500 $\mu \mathrm{M}: 1 \mu \mathrm{M}: 300 \mu \mathrm{M})$ or without stimulation were seeded independently to establish appropriate controls. The CellTiter $96^{\circledR} \mathrm{AQ}_{\text {ueous }}$ One Solution (Promega, Madison, WI, USA) commercial kit was used to determine T-cell proliferation according to the procedure provided in the supplier insert. After incubating the cells for $4 \mathrm{~h}$ at $37{ }^{\circ} \mathrm{C}$ and $5 \% \mathrm{CO}_{2}$, the plate was read on an ELISA plate reader (Corning) at a wavelength of $490 \mathrm{~nm}$. The percentage of T-cell proliferation was determined as follows: \% proliferation $=[$ reading $\mathrm{T}$-cell cultures with conditioned media and anti-CD2/CD3/CD28 beads]/[reading T-cell cultures with anti-CD2/CD3/CD28 beads] $\times 100$.

\section{Determination of IFN- $\gamma$ in activated T-cells}

A total of $2.5 \times 10^{5} \mathrm{CD} 8+$ T-cells were cultured for $48 \mathrm{~h}$ in a 24-well plate (Corning) with $1 \mathrm{ml}$ of IMDM culture medium $+10 \%$ dialyzed FBS in the presence of beads coated with anti-CD2/CD3/CD28 in the ratio 2:1 and in the presence or absence of $20 \mu \mathrm{L}$ of MSCs supernatants. Caffeine $(300 \mu \mathrm{M})$ or ZM241385 $(1 \mu \mathrm{M})$ were added to some wells. Lymphocytes stimulated with beads coated with anti-CD2/CD3/CD28 alone or in the presence of synthetic Ado $(500 \mu \mathrm{M})$, caffeine $(300 \mu \mathrm{M})$, Ado:caffeine (500 $\mu \mathrm{M}: 300 \mu \mathrm{M})$, Ado: ZM241385 (500 mM:1 mM), Ado: ZM241385:caffeine $(500 \mu \mathrm{M}: 1 \mu \mathrm{M}: 300 \mu \mathrm{M})$ or without stimulus were seeded independently to establish appropriate controls. During the last $4 \mathrm{~h}$ of culture, Brefeldin-A (Sigma-Aldrich) was added to a final concentration of $10 \mu \mathrm{M}$ to determine the content of intracellular IFN- $\gamma$. Subsequently, cells were collected, fixed and permeated using the Cytofix/Cytoperm Kit (BD Biosciences, San Jose, CA, USA) kit. T-cells were labeled with anti-IFN- $\gamma /$ FITC and anti-CD8/APC (R\&D Systems, Inc, Minneapolis, MN, USA) monoclonal antibodies, incubated for $30 \mathrm{~min}$ at $4{ }^{\circ} \mathrm{C}$ and washed three times with PBS. The labeled cells were evaluated in a CyAN flow cytometer (Beckman Coulter). A total of $5 \times 10^{4}$ events were acquired to analyze the percentage of CD8+IFN- $\gamma+$ cells using Summit V4.3 software.

\section{cAMP assay}

Measurements of cAMP levels were performed, as described previously [40]. Briefly, CD8+ T-cells $\left(4 \times 10^{5}\right)$ were cultured alone or in the presence of $20 \mu \mathrm{l}$ of each supernatant (total volume of $200 \mu \mathrm{l}$ ). In other cases, synthetic Ado $(500 \mu \mathrm{M})$, caffeine $(300 \mu \mathrm{M})$, Ado:caffeine (500 $\mu \mathrm{M}: 300 \mu \mathrm{M})$, Ado: ZM241385 (500 mM:1 mM), Ado: ZM241385:caffeine (500 $\mu \mathrm{M}: 1 \mu \mathrm{M}: 300 \mu \mathrm{M})$, or the ARs agonist, $5^{\prime}-\mathrm{N}$-ethylcarboxamidoadenosine (NECA; Sigma-Aldrich) $(5 \mu \mathrm{M})$ were seeded independently to establish appropriate controls. The cells were incubated for $30 \mathrm{~min}$ at $37{ }^{\circ} \mathrm{C}$, and the reaction was stopped by addition of $1 \mathrm{~N}$ hydrochloric acid. cAMP levels were determined by ELISA using the Parameter ${ }^{\mathrm{TM}}$ cAMP assay kit (R\&D Systems, Inc, Minneapolis, MN, USA).

\section{In vitro analysis of the suppression of effector CTL activity}

To analyze the suppressor capacity of Ado on effector CTL function, CD8+ T-cells specific for the YMLDLQPETT peptide derived from the E7 HPV-16 protein were obtained using a method previously reported by our group [41]. A total of $1 \times 10^{6}$ CTLs were previously cultured for $3 \mathrm{~h}$ in the presence of synthetic Ado $(500 \mu \mathrm{M})$ or with $20 \mu \mathrm{l}$ of supernatants obtained from MSCs cultured for $5 \mathrm{~h}$ in presence of $5 \mathrm{mM}$ AMP. Subsequently, CTLs were washed and challenged with cells from the T2 lymphoblastic cell line that express empty HLA-A*02:01 molecules on their cell surfaces [42], which were loaded with $10 \mu \mathrm{M}$ YMLDLQPETT peptide.

Target cells (peptide-loaded T2) were labeled with 5(6)-carboxyfluorescein diacetate $N$-succinimidyl ester (CFSE) (Sigma-Aldrich), and CTLs were labeled with CD8-APC antibody (BD Bioscience) following the protocol provided by $\mathrm{BD}$ Bioscience. The cytotoxic activity of effector cells on target cells was determined in the proportions 10:1, 5:1 and 2.5:1 (effector:target) using a cell viability solution (7AAD, Sigma-Aldrich). Viable cells were analyzed under a Coulter CyAN flow cytometer (Beckman Coulter) from the acquisition of 100,000 events by determining the percentage of positive target cells for CFSE/7AAD.

Lymphocytes were independently seeded with medium alone or medium with AMP, synthetic Ado, caffeine (300 $\mu \mathrm{M})$, ZM241385 (1 $\mu \mathrm{M})$, Ado:caffeine (500 $\mu \mathrm{M}: 300 \mu \mathrm{M})$, Ado:ZM241385 (500 mM:1 mM) or Ado: ZM241385:caffeine $(500 \mu \mathrm{M}: 1 \mu \mathrm{M}: 300 \mu \mathrm{M})$ to establish the appropriate controls. A total of $5 \%$ hydrogen peroxide was used in some cases to determine the total lysis of target cells. 
The percentage of lysis was calculated according to the following formula: \% cytotoxicity $=100 \times[$ (experimental lysis (CFSE+, 7AAD+) - basal lysis (CFSE+, 7AAD+)/ (total lysis (CFSE+, 7AAD+) - basal lysis (CFSE+, 7AAD+)].

\section{Statistical analysis}

All numerical data are presented as the mean value \pm SEM of three independent experiments. Comparisons were evaluated by multivariate statistical analysis using GraphPad Prism version 7 (GraphPad Prism software, USA). The difference was considered statistically significant at $\mathrm{P}<0.05$.

\section{Results}

\section{Immunophenotype and differentiation capacity} of NCx-MSCs and CeCa-MSCs

Individual experiments from $\mathrm{NCx}-\mathrm{MSCs}$ and $\mathrm{CeCa}-$ MSCs displayed immunophenotypes and differentiation capacities similar to those reported previously [19]. MSCs from both sources expressed high levels of the characteristic MSCs surface markers CD105, CD90, and CD73 as established by the International Society for Cellular Therapy (ISCT) [2]. Furthermore, the MSCs expressed low levels of HLA-ABC, were HLA-DR-negative and did not express hematopoietic markers such as CD34, CD45 and CD14 or endothelial markers such as CD31 (Fig. 1A). Meanwhile, MSCs from both sources were capable of adipogenic, osteogenic and chondrogenic differentiation (Fig. 1B).

\section{Expression and functional activity of CD39 and CD73 ectonucleotidases in CeCa-MSCs and NCx-MSCs}

In a hypoxic tumor microenvironment, Ado diminishes the ability of effector cells to kill malignant transformed cells [43]. The adenosinergic pathway contributes significantly to the immunosuppressive capacity of MSCs $[44,45]$. We analyzed the expression level of CD39 and CD73 ectonucleotidases in CeCa-MSCs and NCx-MSCs, and we compared their ability to suppress the activation and effector functions of CD8+ T-cells through the production of Ado. CeCa-MSCs exhibited significantly $(\mathrm{P}<0.05)$ higher CD39 and CD73 expression levels than NCx-MSCs (Fig. 2). Through flow cytometry analysis we detected that the mean fluorescence intensity (MFI) for CD39 ectonucleotidase was $68 \pm 25$ in CeCa-MSCs and $25 \pm 7$ in NCx-MSCs, and the MFI value for CD73 ectonucleotidase was $170 \pm 34$ in CeCa-MSCs compared to $89 \pm 24$ in NCx-MSCs (Fig. 2a). Similar results were observed using immunocytochemical analysis, the total expression density (TED) for CD39 ectonucleotidase was $1786 \pm 189$ in CeCa-MSCs and $1146 \pm 206$ in NCxMSCs, and the TED value for CD73 ectonucleotidase was $3480 \pm 375$ in CeCa-MSCs compared to $2189 \pm 258$ in NCx-MSCs (Fig. 2b, c).

Furthermore, samples containing $1 \times 10^{5} \mathrm{MSCs}$ were cultured in the presence of the adenine nucleotides ATP, $\mathrm{ADP}$ and AMP at $5 \mathrm{mM}$ to test the ability of MSCs to generate Ado through the functional activity of CD39 and CD73 ectoenzymes. Aliquots were taken from the supernatants at 60 -min intervals to analyze nucleotide hydrolysis and Ado generation. TLC and UPLC were used for this analysis. According to the expression of both ectoenzymes found in MSCs membranes, after $300 \mathrm{~min}$ of culture in the presence of different nucleotides, $\mathrm{CeCa}-\mathrm{MSCs}$ more efficiently hydrolyzed ATP, ADP and AMP nucleotides to generate Ado from each nucleotide, as shown (by arrows) in the TLC image of the products obtained after elution of the samples in TLC (Fig. 3a).

Furthermore, to determine the amount of Ado generated by MSCs during the culture period with different adenine nucleotides, aliquots were taken from the supernatants, and Ado production was quantified by UPLC. Using synthetic Ado concentrations as reference standards (Fig. 3b), the amount of Ado generated by CeCa-MSCs during the culture period was significantly higher than that produced by the NCx-MSCs (Fig. 3c). Ado concentrations in the supernatants of $\mathrm{CeCa}-\mathrm{MSCs}$ cultured for $5 \mathrm{~h}$ in the presence of ATP, ADP and AMP were $230 \pm 35,320 \pm 42$ and $1950 \pm 216 \mu \mathrm{M}$, respectively, whereas respective concentrations of $53.5 \pm 12.2$, $42.8 \pm 6.5$ and $880 \pm 184 \mu \mathrm{M}$ were found in NCx-MSC supernatants (Fig. 3c). Moreover, MSCs cultured in the absence of nucleotides showed no detectable Ado levels, and the addition of POM-1 (specific inhibitor of CD39) or APCP (specific inhibitor of CD73) decreased the ability of MSCs to hydrolyze the different adenine nucleotides by more than $90 \%$ (Fig. 3a, c). In fact, the low Ado concentrations produced by MSCs cultured in the presence of POM1- or APCP were similar to that obtained when mAbs anti-CD39 or anti-CD73 were added to the cell cultures (Fig. 3d). Moreover, the addition of nucleotides (ATP, ADP and AMP), inhibitors (POM-1 and APCP) or mAbs (anti-CD39 or anti-CD73) to the cell cultures, did not affect the expression of the CD39 and CD73 ectonucleotidases on MSCs cell surfaces (Fig. 3e). These results provide evidence of that Ado produced by MSCs cultures in the presence of adenine nucleotides is due to the enzymatic activity of CD39 and CD73 on MSCs.

\section{Ado produced by CeCa-MSCs strongly inhibited the proliferation and activation of $\mathrm{CD} 8+\mathrm{T}$-cells}

Ado inhibits the activation and cytotoxic effector functions of both NK cells and CD8+ T-cells [32, 38]. CD8+ T-cells were isolated by negative selection from PBMCs from normal donors to determine if the Ado generated 


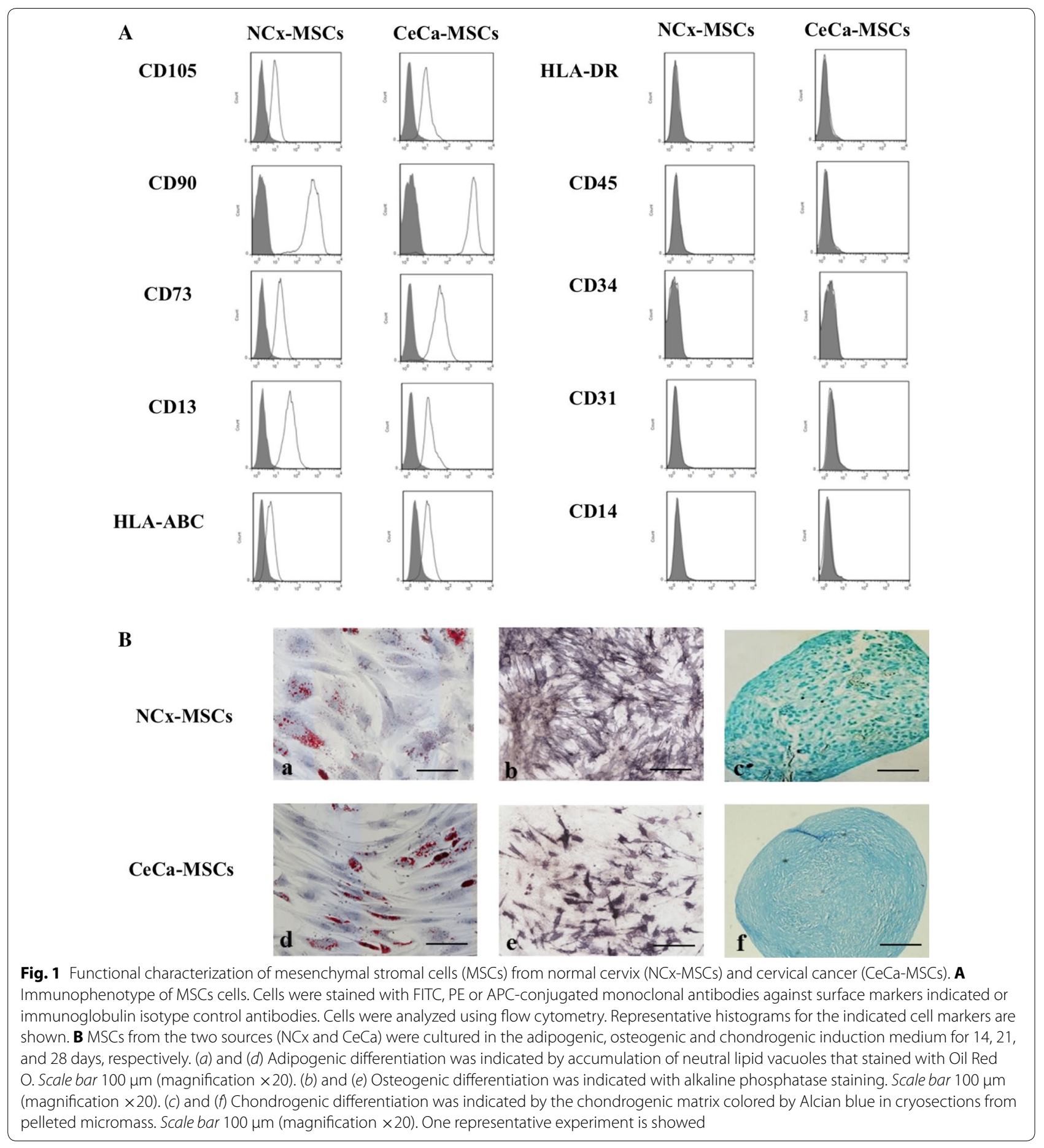

by MSCs was able to inhibit the proliferation and activation of effector T-cells. These isolated CD8+ T-cells were cultured for $72 \mathrm{~h}$ with beads containing anti-CD2/ CD3/CD28 antibodies. This incubation was carried out in the presence of different concentrations of synthetic Ado $(32-1000 \mu \mathrm{M})$ and supernatants obtained from
NCx-MSCs and CeCa-MSCs precultured with adenine nucleotides. Caffeine $(300 \mu \mathrm{M})$, a nonselective inhibitor of the ARs, was added in some cultured plates. In other cases, ZM241385 (1 $\mu \mathrm{M})$, a selective antagonist of the A2A receptor, was added. As shown in Fig. 4a, when using synthetic Ado, the inhibition of CD8+ T-cell 


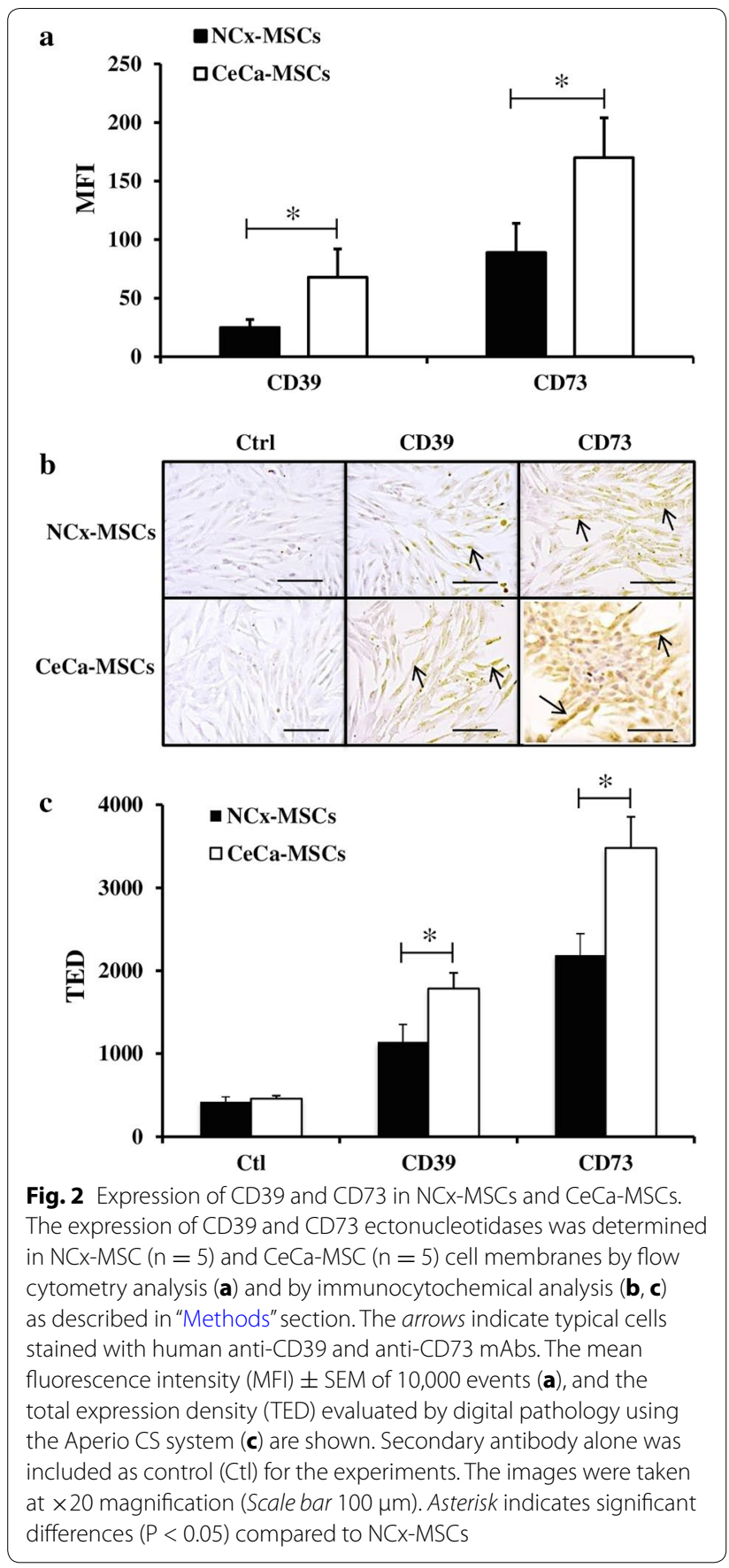

proliferation was proportional to the increase in the concentration of synthetic Ado added to T-cell cultures. An inhibition of proliferation of $50-60 \%$ was found at Ado concentrations of $62-250 \mu \mathrm{M}$. At concentrations higher than $500 \mu \mathrm{M}$, inhibition was greater than 80 \% (Fig. 4a). NCx-MSC supernatants cultured in the presence of AMP, inhibited the proliferation of CD8+ T-cells by approximately $40 \%$, whereas supernatants from $\mathrm{CeCa}$ MSCs doubled their inhibitory capacity, as shown (by bars with diagonal lines) in (Fig. 4b). The Ado concentration in CD8+ T-cell cultures was approximately 250 and $600 \mu \mathrm{M}$ when adding NCx-MSC and CeCa-MSC supernatants, respectively. These concentrations were maintained in subsequent assays. Furthermore, CeCaMSC supernatants cultured for $5 \mathrm{~h}$ in the presence of ATP and ADP inhibited CD8+ T-cell proliferation by approximately $30-40 \%$, as shown by (bars in grey and black) in (Fig. 4b). With supernatants derived from $\mathrm{NCx}$ MSCs, the inhibition was less than $10 \%$ (Fig. 4b). Moreover, the inhibitory effect on CD8+ T-cell proliferation was significantly blocked by adding caffeine $(300 \mu \mathrm{M})$ or ZM241385 $(1 \mu \mathrm{M})$ to CD8+ T-cell cultures in the presence of MSC supernatants, suggesting that the inhibition of CD8+ T-cell proliferation was due to the presence of Ado in the supernatants (Fig. 4b).

To analyze the effect of Ado on CD8+ T-cell activation, these cells were stimulated with beads containing antiCD2/CD3/CD28 antibodies in the presence or absence of synthetic Ado or supernatants from MSCs previously cultured with AMP. After culturing cells for $48 \mathrm{~h}$, we determined the percentage of CD8+IFN- $\gamma+\mathrm{T}$-cells. Approximately $19 \pm 5 \% \mathrm{CD} 8+\mathrm{IFN}-\gamma+\mathrm{T}$-cells were obtained by stimulating CD8+ T-cells in the presence of activation beads. However, $7.3 \pm \%$ of CD8+IFN $-\gamma+$ T-cells were obtained when synthetic Ado $(500 \mu \mathrm{M})$ was added to cultured CD8+ T-cells. The percentage of $\mathrm{CD} 8+\mathrm{IFN}-\gamma+\mathrm{T}$-cells obtained in the presence of $\mathrm{NCx}$ MSC supernatant was $13 \pm 2.5 \%$ and in the presence of CeCa-MSC supernatant was $6 \pm 1.5 \%$ (Fig. 5). Interestingly, the addition of caffeine, the antagonist ZM241385, or both ARs antagonists, to CD8+ T-cell cultures strongly blocked the inhibitory effect of CD8+ T-cell activation produced by MSCs supernatants, suggesting that Ado generated in CeCa-MSC supernatants strongly inhibits the activation of CD8+ T-cells (Fig. 5).

Moreover, we observed that Ado generated in $\mathrm{CeCa}$ MSCs supernatants was able to suppress the activation of CD8+ T cells. Thus, the addition of CeCa-MSCs supernatants to $\mathrm{CD} 8+\mathrm{T}$ cells, induced a strong increase in the level of cAMP in these cells compared with the basal one, interestingly this effect was blocked by the addition of ZM241385, caffeine or both AR antagonists (Fig. 6).

\section{The Ado generated by the CeCa-MSCs strongly inhibits the effector function of CTLS}

The previously reported $[40,46]$ CTL activation and CTL cytotoxic activity measurement system, was used to determine whether Ado generated by $\mathrm{CeCa}$-MSCs affects the effector capacity of CTLs. CD8+ T-cells specific for the antigenic peptide YMLDLQPETT from the sequence 11-20 of the HPV-16 E7 protein with specific affinity to the HLA-A"0201 allele, were cultured for $3 \mathrm{~h}$ in the 

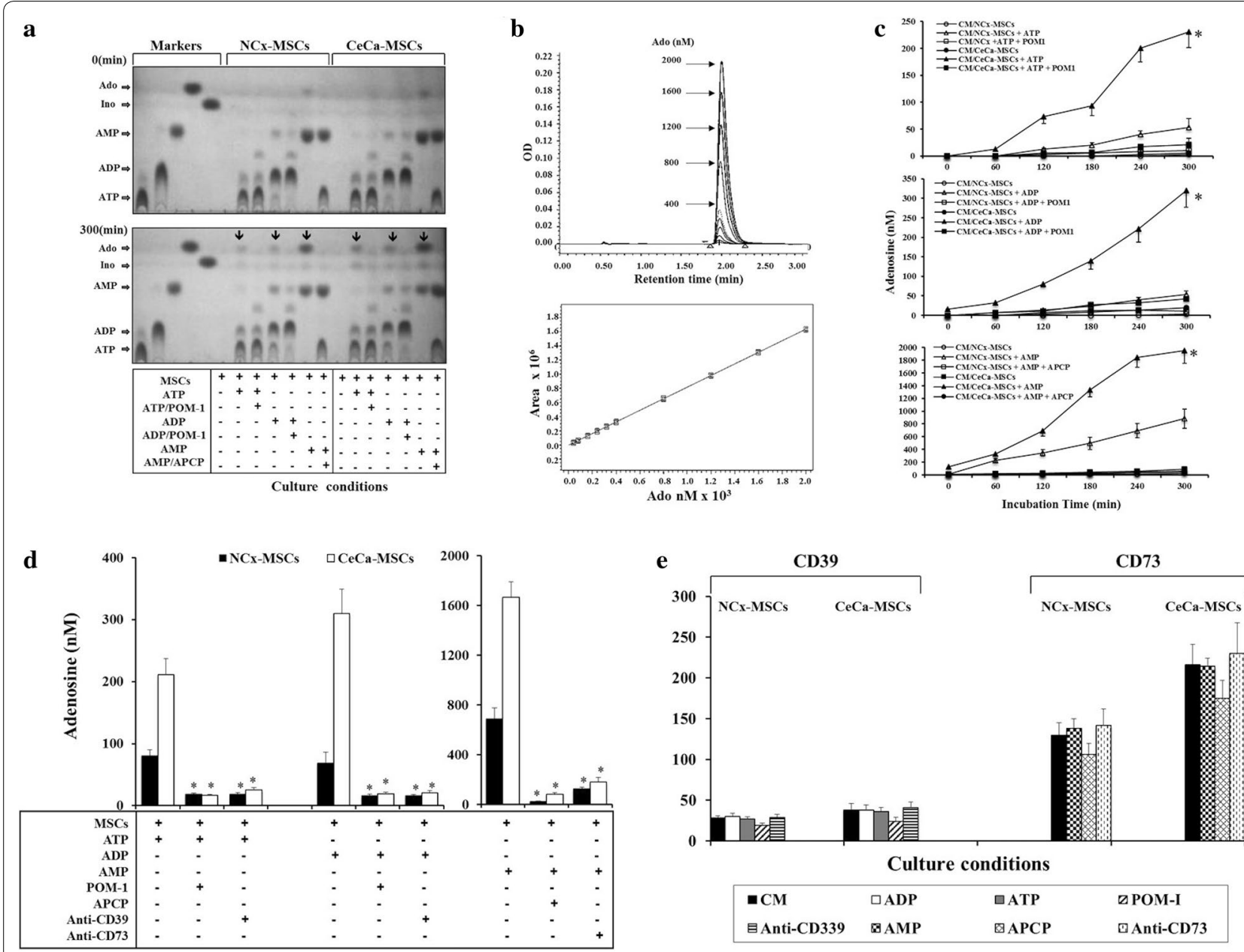

Culture conditions

Fig. 3 Hydrolytic activity of CD39 and CD73 ectonucleotidases expressed in MSCs. A total of $1 \times 10^{5}$ CEMs derived from NCx-MSCs $(n=5)$ and CeCa-MSCs $(n=5)$ were cultured at $37^{\circ} \mathrm{C}$ with $5 \mathrm{mM}$ adenine nucleotides (ATP, ADP or AMP) in the presence or absence of POM-1 (specific CD39 inhibitor) or APCP (specific CD73 inhibitor). a Adenosine produced by the hydrolysis of nucleotides was analyzed by thin layer chromatography (TLC). The ATP, ADP and AMP hydrolysis products (marked with arrows) at the end of MSC culture with different nucleotides are shown. ATP, ADP, AMP, inosine (Ino) and synthetic adenosine were used as markers. b Adenosine contained in supernatant samples was quantified every 60 min by ultra-performance liquid chromatography (UPLC), using standard concentrations of synthetic Ado (upper). A representative linear range between concentration and histogram integral area for Ado is shown (lower). c The concentration of Ado produced by the hydrolysis of ATP (upper), ADP (middle) and AMP (lower) during the period of MSC culture with the respective nucleotides is shown. Asterisk indicates significant $(P<0.001)$ differences compared to NCX-MSCs. d The concentrations of Ado produced by the hydrolysis of adenine nucleotides (ATP, ADP or AMP) after $5 \mathrm{~h}$ of culture of MSCs in the presence of either ectonucleotidase specific inhibitors (POM-1 or APCP) or human mAbs (anti-CD39 and anti-CD73) are shown. Asterisk indicates significant $(P<0.001)$ differences compared to the either CD39 or CD73 basal expression. e The expression of the CD39 and CD73 ectonucleotidases on MSCs cultured during $5 \mathrm{~h}$ alone with culture medium (CM) or in the presence of nucleotides (ATP, ADP and AMP), inhibitors (POM-1 and APCP) and mAbs (anti-CD39 or anti-CD73) is shown. Data are representative of three independent experiments, and the mean \pm SEM are shown

presence of synthetic Ado or supernatants obtained from MSCs cultured for $5 \mathrm{~h}$ in the presence of $5 \mathrm{mM}$ AMP and subsequently challenged against T2 target cells (HLAA*0201+) loaded with peptide YMLDLQPETT. As a positive control of inhibition, CTLs were incubated in the presence of synthetic Ado $(500 \mu \mathrm{M})$. As expected, synthetic Ado significantly inhibited the cytotoxic capacity of CTLs (Fig. 7a). Furthermore, only CeCa-MSC supernatants comparably inhibited the cytotoxic activity of CTLs (Fig. 7b), whereas CTLs cultured in the presence of NCx-MSC supernatants showed no inhibitory effect on the cytotoxic activity of CTLs (Fig. 7c). Interestingly, the addition of either caffeine or ZM241385, or the mixture of both, to CTL cultures in the presence of synthetic Ado 


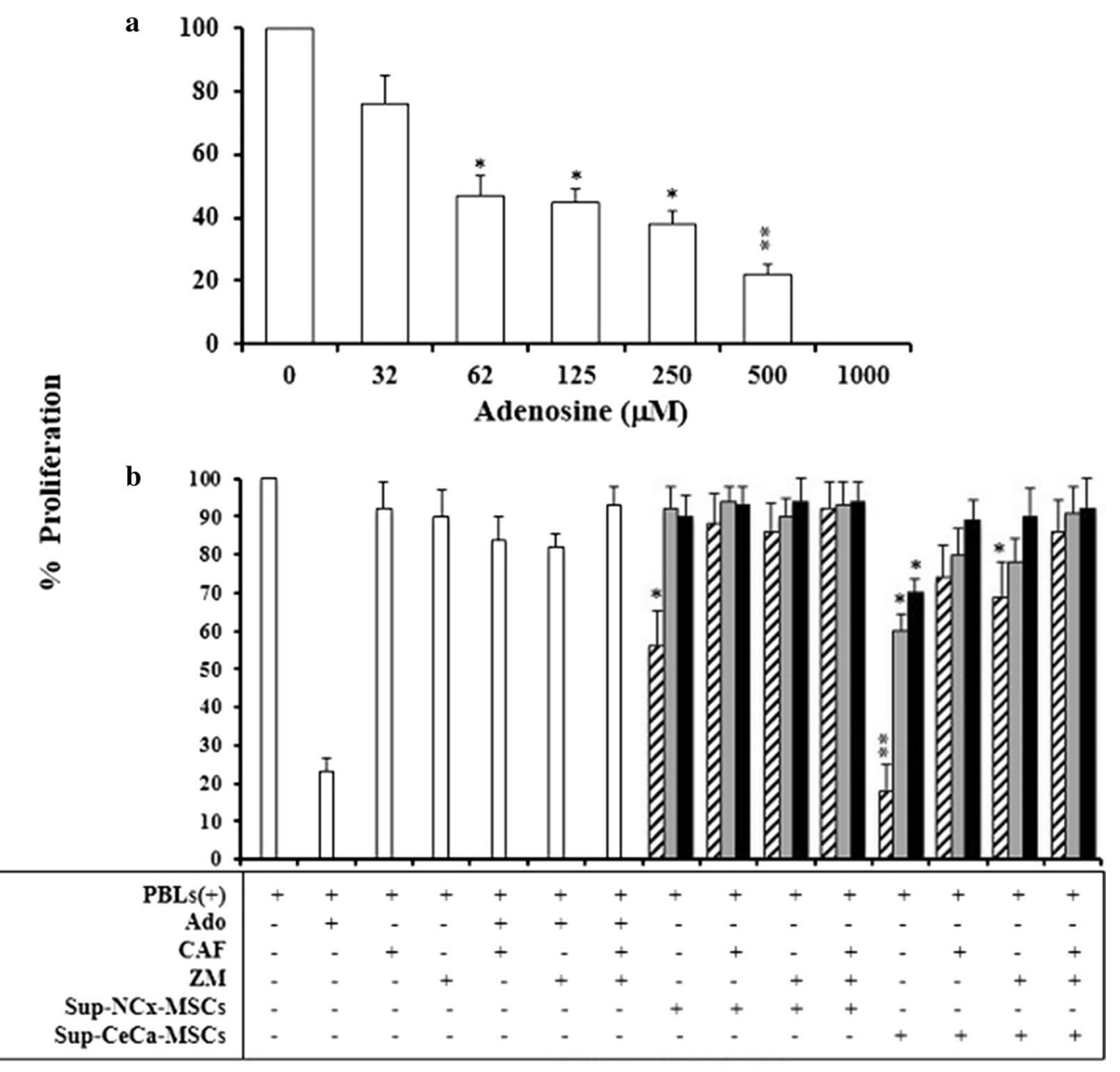

\section{Culture conditions}

Fig. 4 Adenosine generated by CeCa-MSCs strongly inhibits the proliferation of CD8+T-cells. A total of $5 \times 10^{5} \mathrm{CD} 8+$ T-cells obtained by negative selection were cultured with beads containing anti-CD2/CD3/CD28 antibodies in a 2:1 ratio and in the presence of various concentrations of synthetic adenosine (a). Some cells were cultured with supernatants (Sup) obtained from NCX-MSC or CeCa-MSC cultured in the presence of the AMP (bars with diagonal lines), ADP (grey bars) or ATP (black bars), or in the presence of adenine nucleotides plus $300 \mu \mathrm{M}$ caffeine (CAF), a nonselective antagonist of Ado receptors; $1 \mu \mathrm{M}$ ZM241385 (ZM), a selective antagonist of A2A receptor, or CAF:ZM (300 $\mu \mathrm{M}: 1 \mu \mathrm{M})$, as indicated (b). CD8+ T-cells cultured in the presence of $500 \mu \mathrm{M}$ synthetic Ado were used as positive controls of inhibition. After $96 \mathrm{~h}$ of culture, CD8+ T-cell proliferation was determined by a colorimetric method described in "Methods" section. Significant differences* $(P<0.05)$ and ** $(P<0.01)$ were obtained compared with CD8+ T-cells cultured with beads in the absence of Ado (negative control of inhibition). Data are representative of three independent experiments, and the mean \pm SEM are shown

(Fig. 7a) or CeCa-MSC supernatants (Fig. 7b) strongly blocked the inhibitory effect of Ado on cytotoxic CTL activity. Culturing CTLs in the presence of AMP did not affect their effector activity (data not shown).

Our results strongly suggested that the differential expression of CD39 and CD73 ectonucleotidases on the membranes of $\mathrm{CeCa}$-MSCs compared to $\mathrm{NCx}$-MSCs may have an important role in the immunosuppressive capacity of the CTL-mediated anti-tumor immune response through the generation of Ado.

\section{Discussion}

MSCs were described in the early 1970s in the context of regenerative medicine based on their plasticity to differentiate into chondrogenic, adipogenic and osteogenic lineages [47]. However, various immunosuppressive properties of MSCs have recently been described, paving the way for the use of MSCs in immune disorders such as graft versus host disease and multiple sclerosis [48]. Several studies have focused on elucidating MSCs involvement in malignancy development through the 


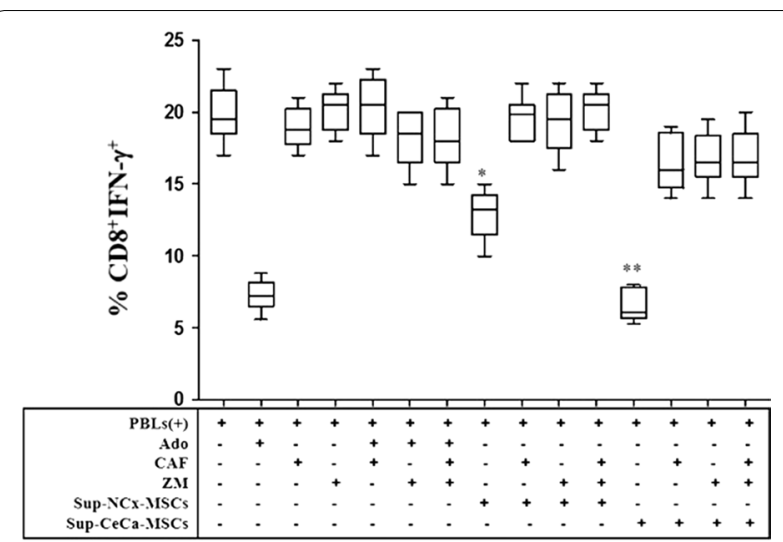

Culture conditions

Fig. 5 Adenosine generated by CeCa-MSCs strongly inhibits CD8+ T-cell activation. A total of $5 \times 10^{5} \mathrm{CD} 8+\mathrm{T}$-cells obtained by negative selection were cultured with beads containing anti-CD2/CD3/CD28 antibodies in a 2:1 ratio and in the presence of supernatants (Sup) obtained from NCX-MSC or CeCa-MSC cultures. Some cells were cultured in the presence of $300 \mu \mathrm{M}$ caffeine (CAF), a nonselective antagonist of Ado receptors, or 1 MM ZM241385 (ZM), a selective antagonist of $\mathrm{A} 2 \mathrm{~A}$ receptor, and combinations of these antagonists, as indicated. CD8+ T-cells cultured in the presence of $500 \mu \mathrm{M}$ synthetic Ado were used as positive controls of inhibition. After $96 \mathrm{~h}$ of culture, the CD8+IFN- $\gamma+$ T-cell percentage was determined. Significant differences $*(P<0.05)$ and $* *(P<0.01)$ were obtained compared with CD8+ T-cells cultured with beads in the absence of Ado (negative control of inhibition). Data are representative of three independent experiments, and the mean \pm SEM are shown

generation of tumors of mesenchymal origin and in the evasion and suppression of the immune system through several mechanisms that have not been fully elucidated $[13,20]$. In the present study, we demonstrated that increased CD39 and CD73 expression in CeCa-MSCs allows these cells to rapidly generate Ado from the adenine nucleotides ATP, ADP and AMP, thereby exerting a strong immunosuppressive capacity on the proliferation, activation and effector functions of CTLs. In contrast, NCx-MSCs only generated Ado from AMP due to the low expression of CD39 in the membrane. In a hypoxic tumor microenvironment, Ado production is mainly mediated by the expression of CD39 and CD73 ectonucleotidases in hematopoietic and non-hematopoietic cells, including endothelial cells, immunosuppressive regulatory T-cells, mononuclear myeloid cells and tumor cells [43]. The ability of CeCa-MSCs to catalyze the ATP, $\mathrm{ADP}$ and AMP nucleotides and to generate immunosuppressive Ado suggests that $\mathrm{CeCa}-\mathrm{MSCs}$ are part of a non-hematopoietic cell population that can significantly contribute to the generation of an immunosuppressive microenvironment. The high CD39 and CD73 expression found in CeCa-MSCs contrasts with results obtained by Saldanha-Araujo et al. [23] and Kerkelä et al. [24], who reported that both BM-MSCs and UCB-MSCs express high levels of CD73 and low levels of CD39 on their surface, enabling them to quickly generate Ado from AMP but not from ATP. However, both studies showed that the addition of activated T-cells to their culture system allowed the generation of Ado from ATP due to the high CD39 expression on activated T-cells, suggesting a cooperative functional activity between MSCs and activated $\mathrm{T}$-cells in the inflammatory microenvironment to generate Ado from ATP released in the damaged tissue $[23,24]$. Therefore, our results suggest that CeCa-MSCs in association with cervical tumor cells, which according to Maldonado et al. [49] and Mello et al. [50] are part of the tumor microenvironment in $\mathrm{CeCa}$, can contribute significantly to the generation of Ado in the presence of high levels of ATP $[49,50]$.

Furthermore, adenosine produced in the tumor microenvironment inhibits the innate and adaptive immune response. The inhibitory effects of Ado on the effector cells of the immune system are mainly induced through the A2A and A2B receptors, which couple to G-proteins and induce an increase in cAMP levels, reducing the production of proinflammatory cytokines and increasing the synthesis of Th2-type cytokines and pro-angiogenic factors such as VEGF [32]. In our study, the proliferation and production of IFN $-\gamma+$ by CD8 + T-cells activated with anti-CD3/CD2/CD28 antibodies and the CTL antigen-specific effector capacity, were inhibited in a dose-dependent manner by Ado generated by MSCs. Supernatants from $\mathrm{CeCa}-\mathrm{MSCs}$ contained approximately $2 \mathrm{mM}$ Ado and had an inhibitory effect higher than $80 \%$, comparable to that observed when similar concentrations of synthetic Ado were added to cultures of activated CD8+ T-cells. In contrast, Ado levels in the NCx-MSC supernatants were less than $600 \mu \mathrm{M}$, with an inhibition below $20 \%$ when added to T-cell cultures. Moreover, the use of A2A receptor antagonists was shown in recent studies to promote the anti-tumor effector activity of CTLs through a perforin-dependent mechanism, suggesting that adenosine signaling through A2A receptors inhibits the production of cytolytic granules by CTLs [51, 52]. Additionally, the antagonism of $\mathrm{A} 2 \mathrm{~A}$ an $\mathrm{A} 2 \mathrm{~B}$ receptors inhibits metastatic progression to lung in a murine model of breast cancer and is dependent on TCD8+IFN- $\gamma+$ activated T-cells, indicating that Ado signaling through these receptors also plays a role in the inhibition of effector T-cell activation [53]. In our study, we also provide evidence of that immunosuppressive activity of Ado contained in CeCa-MSCs supernatants can be through $\mathrm{A} 2 \mathrm{~A}$ receptors on $\mathrm{CD} 8+$ activated $\mathrm{T}$ cells. This is because to the fact the increased level of cAMP induced in activated CD8 $+\mathrm{T}$ cells by the addition of CeCa-MSCs supernatants was blocked (>80\%) 


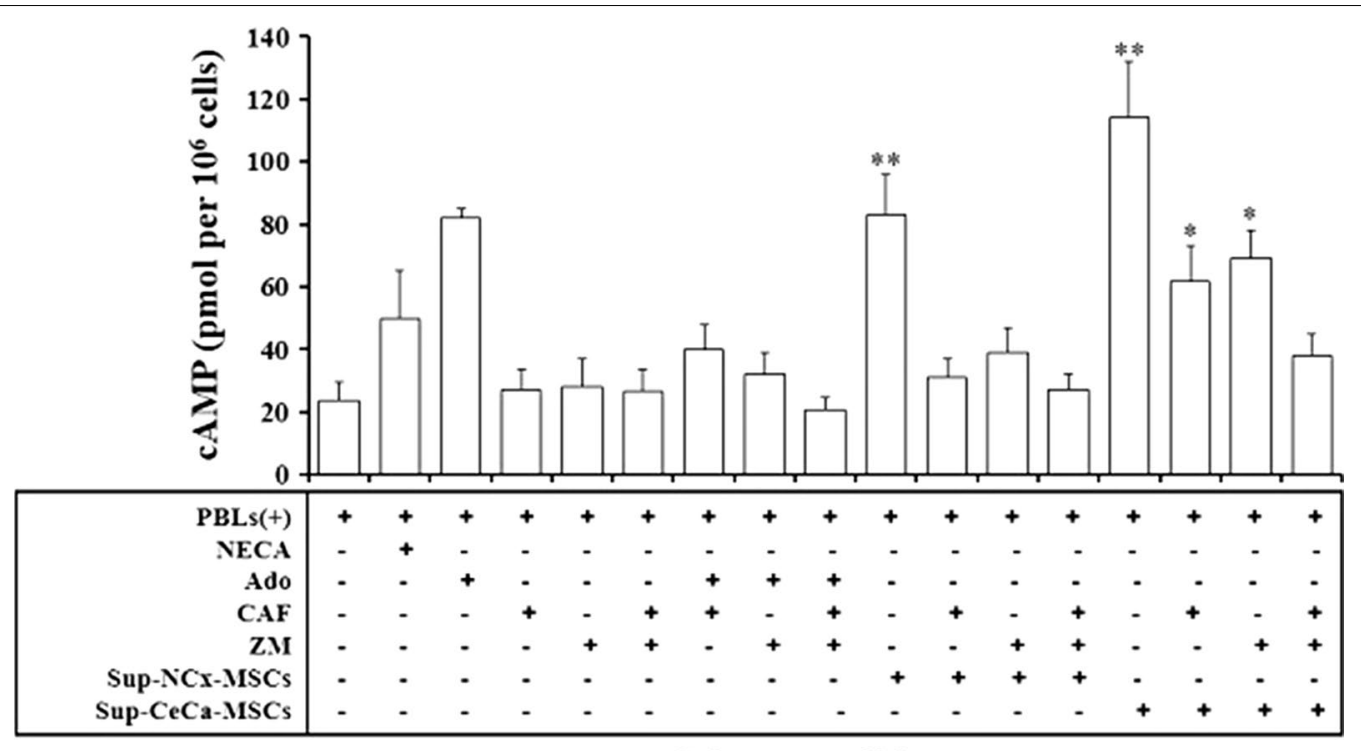

Culture conditions

Fig. 6 Adenosine contained in CeCa-MSC supernatants strongly increases the CAMP levels in CD8+T cells. CD8+ T-cells $\left(4 \times 10^{5}\right)$ previously stimulated with beads containing anti-CD2/CD3/CD28 antibodies in a 2:1 ratio, were cultured during 30 min in the presence of supernatants (Sup) obtained from NCX-MSC or CeCa-MSC cultures. In other cases, cells cultured in the presence of synthetic Ado (500 $\mu \mathrm{M})$, caffeine (300 $\mu$ M),

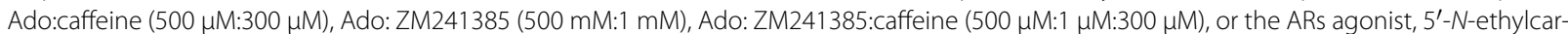
boxamidoadenosine (NECA; Sigma-Aldrich) ( $5 \mu \mathrm{M}$ ) were seeded independently to establish appropriate controls. cAMP levels of the CD8+ T cells were determined as indicated in "Methods" section. Significant differences * $(P<0.05)$ and ** $(P<0.01)$ were obtained compared with CD8+ T-cells cultured with beads in the absence of Ado (negative control of inhibition). Data are representative of three independent experiments, and the mean \pm SEM are shown

by ZM241385 (selective antagonist of A2A receptor) or caffeine (adenosine analog and unspecific blocker of Ado receptors). This strongly suggests that CeCa-MSCs can participate significantly in the immunosuppression of the anti-tumor immune response through the purinergic pathway.

Based on our findings, we propose that the differential expression of CD39 and CD73 ectonucleotidases in $\mathrm{CeCa}-\mathrm{MSCs}$ and NCx-MSCs, and therefore the different capacities to generate Ado, are the result of MSCs conditioning in the tumor microenvironment during the course of the disease. There is substantial evidence that BM-MSCs can migrate to the tumor, thus contributing not only to the formation of tumor stroma but also to the generation of an anti-inflammatory and immunosuppressive microenvironment [13]. For example, a study of ovarian cancer reported that $60-70 \%$ of the cellular content of tumor stroma consisted of BM-MSCs [5]. Other studies have found that TGF- $\beta$ and SDF- $\alpha$ cytokines as well as CXCR6 are important mediators of the migration of BM-MSCs to the tumor microenvironment [54]. Furthermore, the expression of CD39 and CD73 in the tumor microenvironment may be regulated by intrinsic physiological factors. For example, a hypoxic tumor microenvironment can promote the expression of CD73, as hypoxia-inducible factor- $1 \alpha$ (HIF-1 $\alpha)$ interaction with its binding site (hypoxia response element, HRE) in the CD73 gene promoter promotes CD73 expression [55]. The involvement of TGF- $\beta$ in the regulation of CD39+ and $\mathrm{CD} 73+$ expression in various immunosuppressive cell types has also been reported. For example, CD73 expression in immunosuppressor CD4+ T-cells in mice was mainly induced by TGF- $\beta$ [56]. In other studies, both myeloid suppressor cells in mouse tumors [33] and suppressor Th17 cells [57] were induced to co-express high levels of CD39 and CD73 via signaling mediated by TGF- $\beta$, therefore producing Ado as an immunosuppressive mechanism. Persistent infection with HR-HPV is associated with the production of immunosuppressive cytokines such as IL-10 and TGF- $\beta$, which increase in proportion to the degree of disease progression [35-37]. Therefore, we can hypothesize that the TGF- $\beta$ produced during the development of $\mathrm{CeCa}$ may condition resident MSC populations or MSCs that may have migrated from the bone marrow into the tumor site to co-express high levels of CD39 and CD73 ectonucleotidases. In previous studies, we found that $\mathrm{CeCa}-\mathrm{MSC}$ induce the $\mathrm{CeCa}$ derived CaSki and HeLa cell lines to increase synthesis of both IL-10 and TGF- $\beta$ and to decrease expression of HLA class I molecules in the membrane, protecting 

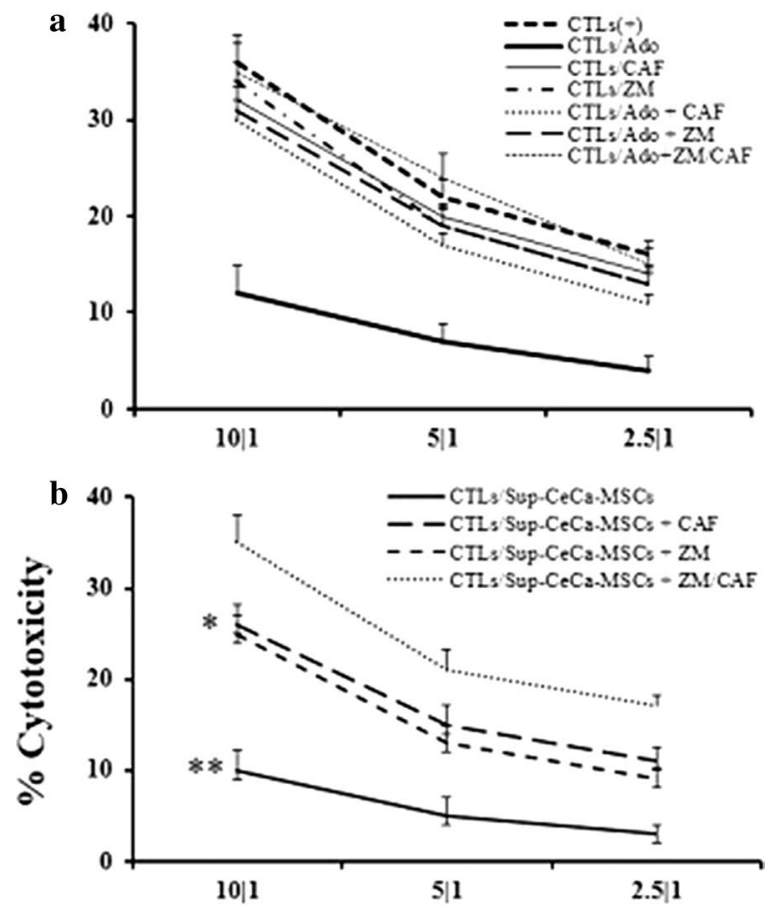

c $407-\mathrm{CTL}_{2} \mathrm{Sup}-\mathrm{NCx}-\mathrm{MSC}$

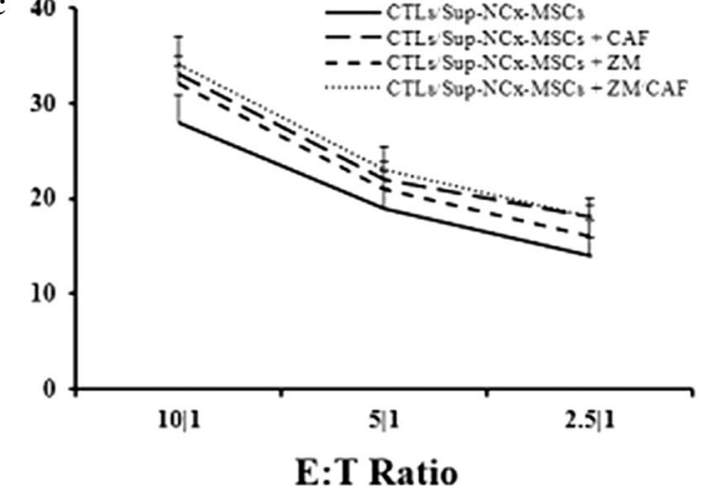

Fig. 7 Adenosine generated by CeCa-MSCs strongly inhibits cytotoxic CTL activity. CTLs specific for the antigenic peptide YMLDLQPETT from the HPV-16 E7 protein were cultured for $3 \mathrm{~h}$ in the presence of synthetic $500 \mu \mathrm{M}$ Ado (a) or supernatants (Sup) obtained from NCx-MSC or CeCa-MSC cultures, (b) and (c) respectively, and subsequently challenged against $\mathrm{T} 2$ cells loaded with the antigenic peptide YMLDLQPETT at 10:1, 5:1 and 2.5:1 ratios of effector:target cells. Some cells were cultured in the presence of $300 \mu \mathrm{M}$ caffeine (CAF), a nonselective antagonist of Ado receptors, or 1 MM ZM241385 (ZM), a selective antagonist of A2A receptor. CTLs cultured for $3 \mathrm{~h}$ in the presence of $500 \mu \mathrm{M}$ synthetic Ado were used as positive controls to analyze the inhibitory effect of Ado on CTL cytotoxic activity. The antagonists CAF and ZM were added to some culture media to block the inhibitory effect of Ado. The cytotoxic activity of CTLs was determined by a cell viability method through a CFSE and 7AAD labeling as indicated in "Methods" section. Significant differences * $(P<0.05)$ and ${ }^{* *}(P<0.01)$ were obtained compared with the cytotoxic activity of CTLs cultured in absence of Ado. Data are representative of three independent experiments, and the mean \pm SEM are shown these cells from immune recognition $[19,46]$. Therefore, the presence of MSCs in the CeCa tumor microenvironment may favor tumor evasion from immune recognition and the immunosuppression of the anti-tumor immune response.

\section{Conclusions}

This study found that increased expression of CD39 and CD73 ectonucleotidases in CeCa-MSC membranes compared to NCx-MSCs was associated with a strong ability to generate Ado from the hydrolysis of ATP, ADP and AMP nucleotides. In contrast, NCx-MSCs generated Ado from only AMP due to the low expression of CD39 in the NCx-MSC membranes. Interestingly, the amount of Ado generated by CeCa-MSCs cultured in the presence of adenine nucleotides significantly increased cAMP levels in activated CD8 $+\mathrm{T}$ cells, likewise, inhibited the proliferation, activation and effector functions of CD8+ antigen-specific T-cells. These results suggest for the first time that the CeCa-MSCs present in the tumor microenvironment may play an important role in the suppression of the anti-tumor immune response in $\mathrm{CeCa}$ through the purinergic pathway.

Considering that the CD39 and CD73 overexpression in tumors has been associated with a worse prognosis as well as to chemotherapy resistance in patients with several malignances [58], our results contribute in elucidate that the overexpression of CD39 and CD73 on CeCa-MSCs may support the immunosuppressive tumor microenvironment to inhibit the function of the antitumoral effector cells, such as CTLs. In consequence some therapeutic strategies should be directed to block or neutralize the functional activity of these ectonucleotidases in $\mathrm{CeCa}$.

\section{Abbreviations}

MSCs: mesenchymal stem/stromal cells; T-MSCs: tumor tissues mesenchymal stem/stromal cells; CeCa: cervical cancer; BM-MSCs: bone marrow mesenchymal stem/stromal cells; UBC-MSCs: umbilical cordon blood mesenchymal stem/stromal cells; EVs: extracellular vesicles; Ado: adenosine; ARs: adenosine receptors; CTLs: cytotoxic CD8+ T lymphocytes; HR-HPV: high-risk human papillomavirus; CeCa-MSCs: cervical cancer mesenchymal stem/stromal cells; NCx-MSCs: normal cervical tissues mesenchymal stem/stromal cells; TLC: chromatography; UPLC: ultra-performance liquid chromatography; PBMC: peripheral blood mononuclear cells; CFSE: 5(6)-carboxyfluorescein diacetate $\mathrm{N}$-succinimidyl ester; MFI: mean fluorescence intensity; HIF-1a: Hypoxia-inducible factor-1a; HRE: hypoxia response element.

\section{Authors' contributions}

MLMG conception and design, analysis and interpretation of data, financial support; RGR, OMR collection of data, data analysis and interpretation; JJMM provision of study material, data analysis and interpretation; BWS data analysis and interpretation, final approval of manuscript; JHM, MAV data analysis and interpretation; LRAI, CADL, VGS collection of data; AMG conception and design, financial support, data analysis and interpretation, manuscript writing, final approval of manuscript. All authors read and approved the final manuscript. 


\begin{abstract}
Author details
${ }^{1}$ Immunobiology Laboratory, Cellular Differentiation and Cancer Unit, FES-Zaragoza, UNAM, Mexico City, Mexico. ${ }^{2}$ Immunology and Cancer Laboratory, Oncology Research Unit, Oncology Hospital, National Medical Center, IMSS, Mexico City, Mexico. ${ }^{3}$ Mesenchymal Stem Cells Laboratory, Oncology Research Unit, Oncology Hospital, National Medical Center, IMSS, Mexico City, Mexico. ${ }^{4}$ School of Medicine, UNAM, Mexico City, Mexico. ${ }^{5}$ Oriente 170 No. 160 Colonia Moctezuma 2a Sección Delegación Venustiano Carranza, 15530 Mexico City, Mexico.
\end{abstract}

\section{Acknowledgements}

We thankfully acknowledge the excellent technical assistance of Luis Alberto Vallejo UDIBI, IPN), María del Carmen Fuentes Castañeda and Juan de Dios Moreno Álvarez (Oncology Research Unit, Oncology Hospital, National Medical Center, IMSS).

\section{Competing interests}

The authors declare that they have no competing interests.

\section{Funding}

We are indebted for CONACYT support to AMG (Grants 106591 and 240635) and DGAPA-PAPIIT support to MLMG (Grant Nos. IN217013 and IN226516); and Mexican Institute of Social Security, IMSS, support to AMG (Grants Nos. 762, 1014 and 1258) are gratefully acknowledged.

Received: 2 June 2016 Accepted: 10 October 2016 Published online: 26 October 2016

\section{References}

1. Pittenger MF, Mackay AM, Beck SC, Jaiswal RK, Douglas R, Mosca JD, et al. Multilineage potential of adult human mesenchymal stem cells. Science. 1999;284:143-7.

2. Dominici M, Le Blanc K, Mueller I, Slaper-Cortenbach I, Marini F, Krause $D$, et al. Minimal criteria for defining multipotent mesenchymal stromal cells. The International Society for Cellular Therapy position statement Cytotherapy. 2006;8:315-7.

3. Gregory CA, Prockop DJ, Spees JL. Non-hematopoietic bone marrow stem cells: molecular control of expansion and differentiation. Exp Cell Res. 2005;306:330-5.

4. Baksh D, Song L, Tuan RS. Adult mesenchymal stem cells: characterization, differentiation, and application in cell and gene therapy. J Cell Mol Med. 2004:8:301-16.

5. Kidd S, Spaeth E, Watson K, Burks J, Lu H, Klopp A, et al. Origins of the tumor microenvironment: quantitative assessment of adipose-derived and bone marrow-derived stroma. PLoS One. 2012;7:e30563.

6. Sun Z, Wang S, Zhao RC. The roles of mesenchymal stem cells in tumor inflammatory microenvironment. J Hematol Oncol. 2014;7:14

7. Caplan Al, Correa D. The MSC: an injury drugstore. Cell Stem Cell. 2011;9:11-5.

8. Katsuda T, Kosaka N, Takeshita F, Ochiya T. The therapeutic potential of mesenchymal stem cell-derived extracellular vesicles. Proteomics. 2013;13:1637-53.

9. Ruster B, Gottig S, Ludwig RJ, Bistrian R, Muller S, Seifried E, et al. Mesenchymal stem cells display coordinated rolling and adhesion behavior on endothelial cells. Blood. 2006;108:3938-44

10. Ren G, Zhao X, Wang Y, Zhang X, Chen X, Xu C, et al. CCR2-dependent recruitment of macrophages by tumor-educated mesenchymal stromal cells promotes tumor development and is mimicked by TNFa. Cell Stem Cell. 2012;11:812-24.

11. Liu Y, Han ZP, Zhang SS, Jing YY, Bu XX, Wang CY, et al. Effects of inflammatory factors on mesenchymal stem cells and their role in the promotion of tumor angiogenesis in colon cancer. J Biol Chem. 2011;286:25007-15.

12. Kabashima-Niibe A, Higuchi H, Takaishi H, Masugi Y, Matsuzaki Y, Mabuchi $Y$, et al. Mesenchymal stem cells regulate epithelial-mesenchymal transition and tumor progression of pancreatic cancer cells. Cancer Sci. 2013;104:157-64.

13. Johann PD, Muller I. Multipotent mesenchymal stromal cells: possible culprits in solid tumors? Stem Cells Int. 2015;2015:914632.
14. McLean K, Gong Y, Choi Y, Deng N, Yang K, Bai S, et al. Human ovarian carcinoma-associated mesenchymal stem cells regulate cancer stem cells and tumorigenesis via altered BMP production. J Clin Investig. 2011;121:3206-19.

15. Wulling M, Delling G, Kaiser $E$. The origin of the neoplastic stromal cell in giant cell tumor of bone. Hum Pathol. 2003;34:983-93.

16. Johann PD, Vaegler M, Gieseke F, Mang P, Armeanu-Ebinger S, Kluba T, et al. Tumour stromal cells derived from paediatric malignancies display MSC-like properties and impair NK cell cytotoxicity. BMC Cancer. 2010;10:501.

17. Gibbs CP, Kukekov VG, Reith JD, Tchigrinova O, Suslov ON, Scott EW, et al. Stem-like cells in bone sarcomas: implications for tumorigenesis. Neoplasia. 2005;7:967-76.

18. Cao H, Xu W, Qian H, Zhu W, Yan Y, Zhou H, et al. Mesenchymal stem cell-like cells derived from human gastric cancer tissues. Cancer Lett. 2009:274:61-71.

19. Montesinos JJ, Mora-Garcia Mde L, Mayani H, Flores-Figueroa E, GarciaRocha R, Fajardo-Orduna GR, et al. In vitro evidence of the presence of mesenchymal stromal cells in cervical cancer and their role in protecting cancer cells from cytotoxic T cell activity. Stem Cells Dev. 2013;22:2508-19.

20. Poggi A, Musso A, Dapino I, Zocchi MR. Mechanisms of tumor escape from immune system: role of mesenchymal stromal cells. Immunol Lett. 2014;159:55-72.

21. Prevosto C, Zancolli M, Canevali P, Zocchi MR, Poggi A. Generation of CD4+ or CD8+ regulatory T cells upon mesenchymal stem cell-lymphocyte interaction. Haematologica. 2007;92:881-8.

22. Di Trapani M, Bassi G, Ricciardi M, Fontana E, Bifari F, Pacelli L, et al. Comparative study of immune regulatory properties of stem cells derived from different tissues. Stem Cells Dev. 2013;22:2990-3002.

23. Saldanha-Araujo F, Ferreira Fl, Palma PV, Araujo AG, Queiroz RH, Covas DT, et al. Mesenchymal stromal cells up-regulate CD39 and increase adenosine production to suppress activated T-lymphocytes. Stem Cell Res. 2011;7:66-74.

24. Kerkela E, Laitinen A, Rabina J, Valkonen S, Takatalo M, Larjo A, et al. Adenosinergic immunosuppression by human mesenchymal stromal cells requires co-operation with T cells. Stem Cells. 2016;34:781-90.

25. Sattler C, Steinsdoerfer M, Offers M, Fischer E, Schierl R, Heseler K, et al. Inhibition of T-cell proliferation by murine multipotent mesenchymal stromal cells is mediated by CD39 expression and adenosine generation. Cell Transplant. 2011;20:1221-30.

26. Ohta A, Sitkovsky M. Role of G-protein-coupled adenosine receptors in downregulation of inflammation and protection from tissue damage. Nature. 2001:414:916-20.

27. Ohta A, Gorelik E, Prasad SJ, Ronchese F, Lukashev D, Wong MK, et al. A2A adenosine receptor protects tumors from antitumor T cells. Proc Natl Acad Sci USA. 2006;103:13132-7.

28. Bruzzese L, Fromonot J, By Y, Durand-Gorde JM, Condo J, Kipson N, et al. NF-kB enhances hypoxia-driven T-cell immunosuppression via upregulation of adenosine A(2A) receptors. Cell Signal. 2014;26:1060-7.

29. Linden J, Cekic C. Regulation of lymphocyte function by adenosine. Arterioscler Thromb Vasc Biol. 2012;32:2097-103.

30. Saze Z, Schuler PJ, Hong CS, Cheng D, Jackson EK, Whiteside TL. Adenosine production by human B cells and B cell-mediated suppression of activated T cells. Blood. 2013;122:9-18.

31. Apasov S, Koshiba M, Redegeld F, Sitkovsky MV. Role of extracellular ATP and P1 and P2 classes of purinergic receptors in T-cell development and cytotoxic T lymphocyte effector functions. Immunol Rev. 1995:146:5-19.

32. Antonioli L, Pacher P, Vizi ES, Hasko G. CD39 and CD73 in immunity and inflammation. Trends Mol Med. 2013;19:355-67.

33. Ryzhov SV, Pickup MW, Chytil A, Gorska AE, Zhang Q, Owens P, et al. Role of TGF-beta signaling in generation of CD39+ CD73+ myeloid cells in tumors. J Immunol. 2014;193:3155-64.

34. Beavis PA, Stagg J, Darcy PK, Smyth MJ. CD73: a potent suppressor of antitumor immune responses. Trends Immunol. 2012;33:231-7.

35. Alcocer-Gonzalez JM, Berumen J, Tamez-Guerra R, Bermudez-Morales V, Peralta-Zaragoza O, Hernandez-Pando R, et al. In vivo expression of immunosuppressive cytokines in human papillomavirus-transformed cervical cancer cells. Viral Immunol. 2006:19:481-91. 
36. Bermudez-Morales VH, Gutierrez LX, Alcocer-Gonzalez JM, Burguete A, Madrid-Marina V. Correlation between IL-10 gene expression and HPV infection in cervical cancer: a mechanism for immune response escape. Cancer Investig. 2008;26:1037-43.

37. Torres-Poveda K, Bahena-Roman M, Madrid-Gonzalez C, Burguete-Garcia Al, Bermudez-Morales VH, Peralta-Zaragoza O, et al. Role of IL-10 and TGF- $\beta 1$ in local immunosuppression in HPV-associated cervical neoplasia. World J Clin Oncol. 2014;5:753-63.

38. Stagg J, Smyth MJ. Extracellular adenosine triphosphate and adenosine in cancer. Oncogene. 2010;29:5346-58.

39. Grunewald JK, Ridley AJ. CD73 represses pro-inflammatory responses in human endothelial cells. J Inflamm. 2010;7:10.

40. Apasov SG, Chen JF, Smith PT, Schwarzschild MA, Fink JS, Sitkovsky MV. Study of $A(2 A)$ adenosine receptor gene deficient mice reveals that adenosine analogue CGS 21680 possesses no $A(2 A)$ receptor-unrelated lymphotoxicity. Br J Pharmacol. 2000;131:43-50.

41. Mora-Garcia Mde L, Duenas-Gonzalez A, Hernandez-Montes J, De la Cruz-Hernandez E, Perez-Cardenas E, Weiss-Steider B, et al. Up-regulation of HLA class-I antigen expression and antigen-specific CTL response in cervical cancer cells by the demethylating agent hydralazine and the histone deacetylase inhibitor valproic acid. J Transl Med. 2006;4:55.

42. Hosken NA, Bevan MJ. Defective presentation of endogenous antigen by a cell line expressing class I molecules. Science. 1990;248:367-70.

43. Young A, Mittal D, Stagg J, Smyth MJ. Targeting cancer-derived adenosine: new therapeutic approaches. Cancer Discov. 2014;4:879-88.

44. Chen X, Shao H, Zhi Y, Xiao Q, Su C, Dong L, et al. CD73 pathway contributes to the immunosuppressive ability of mesenchymal stem cells in intraocular autoimmune responses. Stem Cells Dev. 2016:25:337-46.

45. El Omar R, Xiong Y, Dostert G, Louis H, Gentils M, Menu P, et al. Immunomodulation of endothelial differentiated mesenchymal stromal cells: impact on T and NK cells. Immunol Cell Biol. 2016;94:342-56.

46. Garcia-Rocha R, Moreno-Lafont M, Mora-Garcia ML, Weiss-Steider B, Montesinos JJ, Pina-Sanchez $P$, et al. Mesenchymal stromal cells derived from cervical cancer tumors induce TGF- $\beta 1$ expression and IL-10 expression and secretion in the cervical cancer cells, resulting in protection from cytotoxic T cell activity. Cytokine. 2015;76:382-90.
47. Friedenstein AJ, Deriglasova UF, Kulagina NN, Panasuk AF, Rudakowa SF, Luria EA, et al. Precursors for fibroblasts in different populations of hematopoietic cells as detected by the in vitro colony assay method. Exp Hematol. 1974;2:83-92.

48. Muller I, Kordowich S, Holzwarth C, Isensee G, Lang P, Neunhoeffer F, et al. Application of multipotent mesenchymal stromal cells in pediatric patients following allogeneic stem cell transplantation. Blood Cells Mol Dis. 2008;40:25-32.

49. Maldonado PA, Pimentel VC, Negrini LA, Morsch VM, Schetinger MR. Role of the purinergic system in patients with cervical intraepithelial neoplasia and uterine cancer. Biomed Pharmacother. 2012;66:6-11.

50. Mello Pde A, Filippi-Chiela EC, Nascimento J, Beckenkamp A, Santana DB, Kipper $F$, et al. Adenosine uptake is the major effector of extracellular ATP toxicity in human cervical cancer cells. Mol Biol Cell. 2014;25:2905-18.

51. Koshiba M, Kojima H, Huang S, Apasov S, Sitkovsky MV. Memory of extracellular adenosine A2A purinergic receptor-mediated signaling in murine T cells. J Biol Chem. 1997;272:25881-9.

52. Jin D, Fan J, Wang L, Thompson LF, Liu A, Daniel BJ, et al. CD73 on tumor cells impairs antitumor T-cell responses: a novel mechanism of tumorinduced immune suppression. Cancer Res. 2010;70:2245-55.

53. Cekic C, Sag D, Li Y, Theodorescu D, Strieter RM, Linden J. Adenosine A2B receptor blockade slows growth of bladder and breast tumors. J Immunol. 2012;188:198-205.

54. Quante M, Tu SP, Tomita H, Gonda T, Wang SS, Takashi S, et al. Bone marrow-derived myofibroblasts contribute to the mesenchymal stem cell niche and promote tumor growth. Cancer Cell. 2011;19:257-72.

55. Gao ZW, Dong K, Zhang HZ. The roles of CD73 in cancer. Biomed Res Int. 2014;2014:460654.

56. Regateiro FS, Howie D, Nolan KF, Agorogiannis El, Greaves DR, Cobbold SP, et al. Generation of anti-inflammatory adenosine by leukocytes is regulated by TGF- $\beta$. Eur J Immunol. 2011:41:2955-65.

57. Martin F, Apetoh L, Ghiringhelli F. Controversies on the role of Th17 in cancer: a TGF- $\beta$-dependent immunosuppressive activity? Trends Mol Med. 2012;18:742-9.

58. Antonioli L, Yegutkin GG, Pacher P, Blandizzi C, Haskó G. Anti-CD73 in cancer immunotherapy: awakening new opportunities. Trends Cancer. 2016:2:95-109

\section{Submit your next manuscript to BioMed Central and we will help you at every step:}

- We accept pre-submission inquiries

- Our selector tool helps you to find the most relevant journal

- We provide round the clock customer support

- Convenient online submission

- Thorough peer review

- Inclusion in PubMed and all major indexing services

- Maximum visibility for your research

Submit your manuscript at www.biomedcentral.com/submit 